\title{
МОДЕЛЮВАННЯ ПРОЦЕСУ ЗАРЯДУ БАСЕЙНА-АКУМУЛЯТОРА ГІДРОАКУМУЛЮВАЛЬНОЇ ЕЛЕКТРОСТАНЦЇ̈ ВІД ВІТРОВОДОНАСОСНОЇ УСТАНОВКИ
}

\section{С.Т. Пазич}

Інститут відновлюваної енергетики НАН України 02094 вул. Гната Хоткевича, 20А, м. Київ

3 ростом частки відновлюваних джерел в електроенергетичної мережі Украӥни, відбувається негативний вплив на якість електричної енергії так і на саму мережу. Одним із варіантів ефективної інтеграції відновлюваних джерел в електроенергетичну мережу ие акумулювати ї̈ енергію з подальшим використанням. Оскільки основною проблемою відновлюваних джерел являсться ї̈ непостійність і пульсачія в часі, то ї̈ акумулювання в такі періоди прийнятний варіант. В Украйні найбільщу частку по виробітку за рік займають вітроелектричні станиії, щзо в основному знаходяться на півдні України. Саме там концентрація великих вітроелектричних станцій зумовлюють нестаціонарну роботу електричної мережі, щэо в свою чергу призводить до їх відключення при великих пульсачіях генерування електричної енергії. Акумулювання енергії вітру можливе в різних виконаннях, але в даному дослідженні вивчається варіант з гідроакумулюванням цієї енергії для подальшим використанням через гідравлічну турбіну. Тобто досліджуватиметься проиес перетворення енергії вітру в кількісні показники накопичення води протягом визначеного часу. В якості об'єкту дослідження виступатиме вітроводонасосна установка. Моделювання такого процесу відбуватиметься з поєднання трьох складових: моделі вітру, модель вітровоі турбіни, модель насосу. Моделювання здійснюватиметься для різних потужностей насосу за постійної потужності вітроустановки для визначення найефективнішого варіанту роботи вітроводонасоної установки. Для співвіднотення різних варіантів вітроводонасосної установки з різними потужностями насосів використовуватимемо відносні одиниці виміру, оскільки характеристики насосів в відносних одинииях ідентичні в межах одного класу. Параметром, яким буде оцінюватись робота вітроводонасосної установки служитиме річна величина продуктивності даної установки у відсотковому відношенні за річного розподілу енергії вітру для обраного регіону. Робота установки моделюватиметься тільки за номінального режиму роботи з урахуванням пульсацій вітру та обмежень в моделюванні роботи вітрової турбіни $і$ насосу 3 досвіду їх експлуатації. Бібл. 25.,табл. 3, рис. 4.

Ключові слова: вітроводонасосна установка, механічна характеристика, модель, момент, подача, пульсаиіі.

\section{MODELING OF THE CHARGE PROCESS OF THE UPPER RESERVOIR OF THE PUMP HYDROELECTRIC ENERGY STORAGE FROM THE WIND PUMP INSTALLATION}

\author{
S. Pazych \\ Institute of Renewable Energy, NAS of Ukraine \\ 02094, st. Hnata Khotkevycha 20A, Kyiv, Ukraine
}

With the growing share of renewable sources in the electricity grid of Ukraine, negative impact on the quality of electricity and on the grid itself begins. One of the options for efficient integration of renewable sources into the power grid is to accumulate this energy with subsequent use. Since the main problem of renewable sources is inconsistency and pulsation over time, it's accumulation in such periods is an acceptable option. In Ukraine, the largest share of output per year is occupied by wind power plants, which are mainly located in the south of Ukraine. It is there the concentration of large wind power stations causes the unsteady operation of the electric network, which in turn leads to their shutdown at large pulsations of generation of electric energy. The accumulation of wind energy is possible in various designs, but in this study an option is explored with the accumulation of this energy for subsequent use through a hydraulic turbine. That is, the process of converting wind energy into quantitative indicators of water accumulation over a specified time will be researching. As a research object, a wind pump installation will act. The simulation of this process will be based on a combination of three components: a wind model, a wind turbine model, a pump model. The simulation will be carried out for various pump capacities at a constant wind power level to determine the most efficient version of the wind pump installation. For the ratio of different variants of the wind pump installation with different pump capacities, relative units of measurement will be used, since the characteristics of the pumps in relative units are identical within the same class. The parameter that will be evaluated for the operation of the wind pump installation will be the annual value of the performance of this installation in per cent for the annual distribution of wind energy for the selected region. The operation of the installation will be modeled only for its nominal operating mode, taking into account wind ripples and constraints in modeling the operation of the wind turbine and the pump from the experience of their operation. References 25 , table 3, figures 4.

Keywords: wind pump installation, mechanical characteristics, model, torque, pump feed, pulsations.

(C) С.Т. Пазич, 2019

Відновлювана енергетика. 2019. № 2 


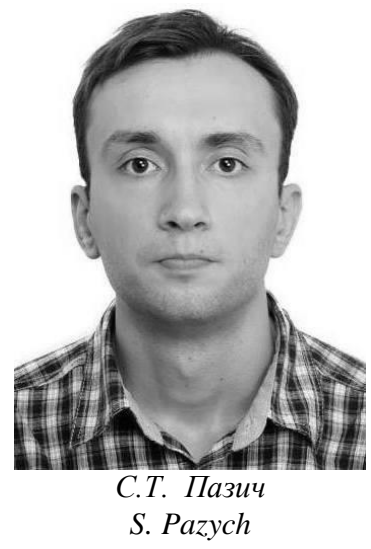

Перелік умовних позначень:

ВНУ - вітроводонасосна установка

ВТ - вітрова турбіна;

J - момент інерції;

Фвт - частота обертання вітрової турбіни;

Мв - момент вітрової турбіни;

Мн - момент насосу.

Вступ. Використання енергії вітру для подачі води має велику історію експлуатації та досліджень [1-4]. 3 ростом частки відновлюваних джерел в Україні постає питання їх ефективного використання при стохастичному характері надходження відновлюваної енергії. Одним із рішень цієї проблеми $є$ акумулювання енергії вітру 3 подальшим іiі використанням [5-12]. На даний час акумулювання енергії вітру практично не реалізовується в силу схемо-технічних рішень, таких як робота на мережу, але частка вітроенергетики зростає і iї робота незабаром суттєво впливатиме на неї. В даній роботі розглянуто варіант акумулювання енергії вітру шляхом гідроакумулювання води на прикладі застосування вітроводонасосної установки (ВНУ). Автором було досліджено моделювання динамічних процесів ВНУ в першому наближенні в абсолютних величинах виміру в середовищі Matlab Simulink $[13,14]$ для нестаціонарних режимів роботи 3 урахуванням пульсацій вітру [15].

Постановка задачі. Дослідимо використання енергії вітру для іiі гідроакумулювання через роботу ВНУ 3 урахуванням пульсацій вітру. Складові частини ВНУ вітрова турбіна (ВТ) і відцентровий насос моделюються за різних співвідношень потужності насосу для визначення найефективнішого варіанту роботи ВНУ за сталої потужності ВТ 3 жорстким механічним зв'язком вала ВТ і насосу. Роботу ВНУ моделюємо при номінальному режимі. Досліджуваними параметрами ВНУ будуть: частота обертання ВТ та подача насоса в часі з урахуванням пульсацій вітру. На основі отриманих даних проводиться аналіз роботи ВНУ за визначений відрізок часу та формулюватиметься кількісні результати продуктив-

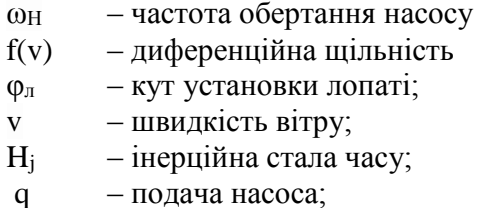

ності ВНУ щодо наповнення умовного басейнаакумулятора гідроакумулювальної станції.

Теоретичні положення. Оцінку використання енергії вітру для акумулювання води протягом року будемо виконувати згідно положень $[16,17]$. В даному дослідженні цей параметр визначається, як сумарний показник подачі за всієї частоти розподілу швидкості вітру протягом року:

$$
\mathrm{W}=\sum_{\mathrm{j}=\mathrm{n}}^{s}\left(\mathrm{q}_{\mathrm{j}} \cdot \mathrm{f}\left(\mathrm{v}_{\mathrm{j}}\right)\right),
$$

де $\mathrm{q}_{\mathrm{j}}$ - подача насосу при $\mathrm{j}$ градації швидкості вітру за рік, $f\left(v_{j}\right)$ - частота тривалості ј градації швидкості вітру за рік; s,n - порядкові номери градацій швидкості вітру.

Подача насосу для кожної окремої градації вітру з урахуванням пульсацій вітру будемо визначати на 10 хвилинному інтервалі часу, згідно нормативної бази [18].

$$
\mathrm{q}_{\mathrm{j}}=\int_{\mathrm{t} 1}^{\mathrm{t} 2} \mathrm{q}\left(\mathrm{v}_{\mathrm{j}}\right) \mathrm{dt},
$$

де $t_{1}, t_{2}-$ час початку і кінця вимірювання подачі; $\mathrm{v}_{\mathrm{j}}$ - миттєве значення швидкості вітру для $\mathrm{j}-$ градації вітру; q( $\left.\mathrm{v}_{\mathrm{j}}\right)$ - значення подачі в кожний момент часу для визначеної градації швидкості вітру.

Розподіл вітрового потоку за рік наведемо у вигляді диференційної щільності середньорічної швидкості вітру двопараметричним розподілом Вейбула.

$$
\mathrm{f}(\mathrm{v})=\left\{\begin{array}{cc}
\frac{\alpha}{\gamma} \cdot\left(\frac{\mathrm{v}}{\gamma}\right)^{\alpha-1} \cdot \mathrm{e}^{-\left(\frac{v}{\gamma}\right)^{\alpha}}, \mathrm{v} \geq 0, \\
0, & \mathrm{v}<0
\end{array}\right\},
$$


де $\gamma$ i $\alpha$ - коефіцієнти розподілу Вейбула, v швидкість вітру.

Модель швидкості вітру з урахуванням пульсацій моделюється в (4), [20,21].

$$
\mathrm{v}(\mathrm{t})=\mathrm{v}_{\mathrm{cp}}+\mathrm{v}^{\prime}(\mathrm{t})=\tau^{-1} \int_{0}^{\tau} \mathrm{v}(\mathrm{t}) \mathrm{dt}+\mathrm{v}^{\prime}(\mathrm{t}),
$$

де $\mathrm{v}(\mathrm{t}), \mathrm{v}_{\mathrm{cp}}$ - миттєве $\mathrm{i}$ середнє значення швидкості вітру; $\tau-$ інтервал осереднення швидкості вітpy; v’(t) - пориви швидкості вітру відносно середнього значення.

Оскільки миттєве значення подачі (q) залежить від частоти обертання насосу, то необхідно вирішувати рівняння обертового руху ВНУ [19].

$$
\begin{gathered}
\mathrm{J} \frac{\mathrm{d} \omega_{\mathrm{BT}}}{\mathrm{dt}}=\mathrm{M}_{\mathrm{BT}}\left(\mathrm{v}(\mathrm{t}), \omega_{\mathrm{BT}}(\mathrm{t}), \varphi_{\text {Л }}\right)- \\
-\sum \mathrm{M}_{C}-\mathrm{M}_{\mathrm{H}}\left(\omega_{\mathrm{H}}(\mathrm{t})\right),
\end{gathered}
$$

де $\mathrm{J}$ - сумарний момент інерції всіх обертових частин, $\omega_{\text {BT }}(\mathrm{t})$ - частота обертання BT, $\omega_{\mathrm{H}}(\mathrm{t})$ - частота обертання насоса, тей ВТ, М $\mathrm{v}(\mathrm{t})$ - миттєве значення швидкості вітру, $\sum \mathrm{M}_{\mathrm{C}}-$ сумарний момент опору обертових частин.

Для дослідження ВНУ 3 насосами різної потужності представимо вираз (5) у відносних одиницях. Перевагою відносних одиниць $є$ те, що характеристики насосу різної потужності практично ідентичні в межах одного типу насосів.

Приведення виразу (5) до відносних одиниць здійснимо розділивши його по черзі на номінальний момент навантаження, яким виступає насос-

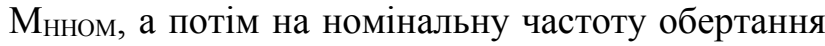

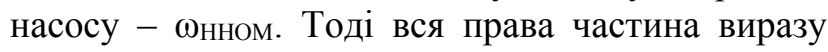
буде приведена до відносного моменту та частоти обертання насосу. Ліва частина рівняння, а саме інерція всіх обертових частин і двох дільників утворюють інерційну сталу часу (6). Узгодження частоти обертання ВТ і насосу здійснимо за допомогою жорсткого механічного зв'язку між валом ВТ і насосу без мультиплікатора, тим самим прирівнявши їх частоту обертання у відносних

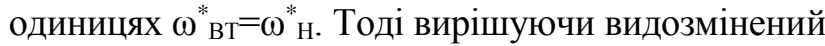
вираз (5), отримаємо вираз розрахунку частоти обертання насосу у відносних одиницях (7).

$$
\begin{aligned}
\mathrm{H}_{\mathrm{j}} & =\mathrm{J} \frac{\omega_{\mathrm{BTHOM}}}{\mathrm{M}_{\mathrm{BTHOM}}}, \\
\omega_{\mathrm{BT}}^{*} & =\frac{1}{\mathrm{H}_{\mathrm{j}}} \int_{0}^{t}\left[\mathrm{M}_{\mathrm{BT}}^{* *}\left(\mathrm{v}(\mathrm{t}), \omega_{\mathrm{BT}}^{*}(\mathrm{t}), \varphi_{\text {Л }}\right)-\right. \\
& \left.-\sum \mathrm{M}_{C}^{*}-\mathrm{M}_{\mathrm{H}}^{*}\left(\omega_{\mathrm{H}}^{*}(\mathrm{t})\right)\right] \mathrm{dt},
\end{aligned}
$$

де $\mathrm{H}_{\mathrm{j}}$ - інерційна стала часу системи; $\mathrm{M}^{* *}{ }_{\text {вт }}$ - відносний момент ВТ без урахування втрат; $\mathrm{M}^{*}{ }^{-}$ відносний момент насосу; $\sum \mathrm{M}_{\mathrm{C}}{ }^{-}$відносний сумарний момент опору; $\omega^{*}{ }_{\text {вт }}(\mathrm{t}), \omega^{*}{ }_{\mathrm{H}}(\mathrm{t})-$ відносна частота обертання ВТ і насосу.

Модель ВТ для розрахунку іï механічної характеристики наведена в [23]. Модель відцентрового насоса представлена залежностями механічного моменту і подачі води від частоти обертання при сталому напорі $[24,25]$.

Для моделювання сумісної роботи ВТ і насосу (7) приймаємо величину механічних втрат в розмірі $20 \%$ від номінального відносного моменту навантаження $\mathrm{M}^{*}$. Значення втрат розділено на дві складові - це постійні втрати на тертя із значенням - 5\% та динамічні втрати $-15 \%$. Оскільки ВТ виступає обертовим рушієм системи ВНУ, то відносна механічна характеристика ВТ 3 урахування втрат $\mathrm{M}_{\text {вт }}^{*}\left(\omega^{*}{ }_{\text {вT }}\right)$ при номінальних показниках $\varphi_{л}=1^{\circ}, \mathrm{v}_{\text {ном }}=9 \mathrm{~m} / \mathrm{c}$ на висоті 10 м над рівнем Землі, наведена на рис.1, де також представлена характеристика насосу $\mathrm{M}^{*}{ }_{\mathrm{H}}\left(\omega^{*}{ }_{\mathrm{H}}\right)$ в номінальному режимі 3 їх перетином в точці $M_{\text {втном }}^{*}=M^{*}{ }_{\text {нном}}=1$ при $\omega^{*}{ }_{\text {вт }}=\omega^{*}{ }_{\mathrm{H}}=1$ (точка Б). Характеристика подачі насосу $q^{*}\left(\omega^{*}\right)$ при сталому напорі (рис.1) має стрімкий характер і в номінальному режимі також перетинає точку Б.

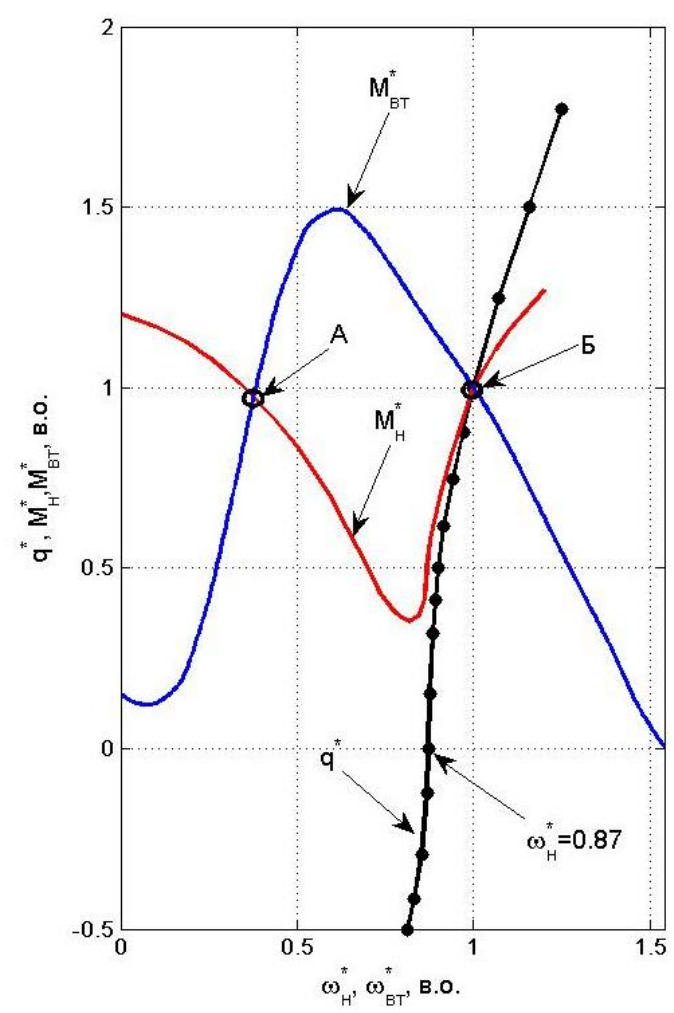

Рис. 1. Сумісна механічна характеристика ВТ і відцентрового насосу.

Fig. 1. Compatible mechanical characteristics of the wind turbine and the centrifugal pump.

Подача відцентрового насосу має позитивний знак при $\omega^{*}{ }_{\mathrm{H}} \geq 0,87$, а при $\omega^{*}{ }_{\mathrm{H}}<0,87$ насос працює в 
режимі гідравлічного гальма. Цей режим в даній моделі спрощений, якщо $\omega^{*}$ н впаде нижче зазначеного рівня, то подача в досліджувані моделі прийматиме нульові значення $\left(\mathrm{q}^{*}=0\right)$. Суміщенні механічні характеристики ВТ і насосу графічним способом окреслюють їх точки перетину (А та Б, рис.1), що демонструє межі роботи ВТ і насосу в функції частоти обертання. При умові $\omega^{*}{ }_{\mathrm{H}}<0,377$ (зліва від точки А) робота ВНУ неможлива внаслідок недостатнього рушійного моменту ВТ.

Для розв'язку виразу (7) на базі моделей вітpy, ВТ і насосу було використано прикладний пакет Matlab 3 розширенням Simulink. Моделювання проводилось із обмеженнями за кожним зазначеним варіантом.

Запроваджені наступні обмеження на модель генерування вітрового потоку [21]:

- значення швидкості вітру моделюватимуться з градаціями $\mathrm{v}_{\mathrm{cp}}$ від 1 до $25 \mathrm{~m} / \mathrm{c}$;

Обмеження яке застосоване на модель ВТ, грунтується на іiі роботі тільки в номінальному режимі (точка Б рис.1). Дане обмеження має за мету дослідити тільки режими роботи ВТ без врахування пускових чи інших нестаціонарних режимів.

Робота насосу моделюватиметься відповідно до умови роботи ВТ в номінальному режимі (точка Б рис.1). Обмеження носитимуть конструктивну складову, обумовлену досвідом експлуатації насосів:

- верхня межа подачі насосу $\mathrm{q}^{*}=1.44$, викликана конструктивною міцністю насосу;

- верхня межа $\omega^{*}$, яку може розвивати наcoc, не має перевищувати $20 \%$ понад номінальних значень $\omega^{*}$ н, але в зв'язку із стрімким характером $\mathrm{q}^{*}\left(\omega^{*}\right)$ значення $\mathrm{q}^{*}=1.44$ настає при $\omega^{*}{ }_{\mathrm{H}}=1,136$;

- $\quad$ при $\omega^{*}{ }_{\mathrm{H}} \leq 0,87$ модель насосу показуватиме нульові значення подачі $q^{*}=0$, оскільки від'ємні значення подачі не моделюються;

Обмеження для сумісної роботи ВТ з насосом меншої потужності від номінального, наведені в табл.1. Насоси меншої потужності моделюватимуться з номінальними значеннями моменту і подачі на $20 \%, 40 \%$ та $60 \%$ меншими від номіналу базисного значення $\mathrm{M}_{\text {нном }}^{*}=1, \omega_{\text {нном}}^{*}=1$.

Таблиця 1. Обмеження параметрів моделювання подачі насосу.

Table 1. Limitation of pump feed simulation parameters.

\begin{tabular}{|c|c|c|c|c|}
\hline \multirow{2}{*}{ Обмеження } & \multicolumn{4}{|c|}{ Відносна номінальна потужність насосу } \\
\cline { 2 - 5 } & 1 & 0,8 & 0,6 & 0,4 \\
\hline Подача води q ${ }^{*}$, в.о. & $0 \leq \mathrm{q}^{*}{ }_{1} \leq 1,44$ & $0 \leq \mathrm{q}^{*}{ }_{0,8} \leq 1,152$ & $0 \leq \mathrm{q}^{*} 0,6 \leq 0,864$ & $0 \leq \mathrm{q}^{*}{ }_{0,4} \leq 0.576$ \\
\hline Частота обертання, $\omega^{*}$ н. в.о. & \multicolumn{4}{|c|}{$0,87 \leq \omega^{*}{ }^{*} \leq 1,136$} \\
\hline
\end{tabular}

Розрахункові результати. Результат рішення виразу (7) на визначеному інтервалі часу представлено у вигляді динаміки зміни частоти обертання ВТ і подачі при різних значень потужністю насосу (рис.2) із зазначеними середньою швидкістю вітру цієї градації й відповідним кутом установки лопаті при цій градації швидкості вітру 3 урахуванням пульсацій і вище зазначених обмежень. Співвідношення потужностей ВТ і насосу наведені на рис.2: $\mathrm{a}-1$ до $1 ; \mathrm{b}-1$ до 0,$8 ; \mathrm{c}-1$ до 0,$6 ; \mathrm{d}-1$ до 0,4 .

Зміни $\omega^{*}$ вт на рис. 2 для насосів різної потужності в середньому менше одиниці, а не дорівнює йому. Це обумовлено поривами вітру, які викликають вихід досліджуваних параметрів за номінальні показники. Тому кути установки лопаті для всіх варіантах такі, при яких модель стабільно працює на всьому інтервалі часу. Стрімкий характер зміни $\mathrm{q}^{*}\left(\omega_{\mathrm{H}}^{*}\right)$ в межах додатних значень подачі на всіх прикладах різко змінюється а залежності від впливу пульсацій вітру. Робота швидкохідної ВТ з насосом виявила, що модель не працює вже на швидкостях вітру в діапазоні 17 м/с в зв'язку з відхиленням v(t) і набуття нею значення в 0,9 раз і менше від $\mathrm{v}_{\mathrm{cp}}$, де ВТ не в змозі розвинути потрібний момент для роботи сис- теми. Найважчі режими припадають на зону низьких швидкостей вітру, де регулювання кутом ВТ вже практично не впливає, оскільки із-за зменшення моменту ВТ зменшується його частота обертання, що призводить до зупинки роботи ВНУ. Найкращі показники роботи моделі ВНУ протягом 10-хвилинного інтервалу часу були досягнуті при номінальних значеннях вітру і вище завдяки регулюванню кута установки лопаті.

За даними багаторічних спостережень метеопостів для півдня України [20] середньорічна швидкість вітру коливається в межах $4-5$ м/с на висоті 10 м над рівнем землі. Для трьох характерних пунктів спостереження на півдні України в табл.2 наведені дані коефіцієнтів двопараметричного розподілу Вейбула, а також їх середні значення.

Диференційна щільність середньорічної швидкості вітру двопараметричного розподілу Вейбула (3) наведена на рис.3 за даними середнього значення коефіцієнтів $\gamma$ і $\alpha$ та $\mathrm{v}_{\mathrm{cp}}$ табл. 2, Даний розподіл на інтервалі швидкості вітру 1-25 м/с містить 95\% потенціалу енергії вітру, а на ділянці швидкості вітру $25 \rightarrow \infty$ міститься інші $5 \%$ в відповідною ймовірністю по розподілу. 

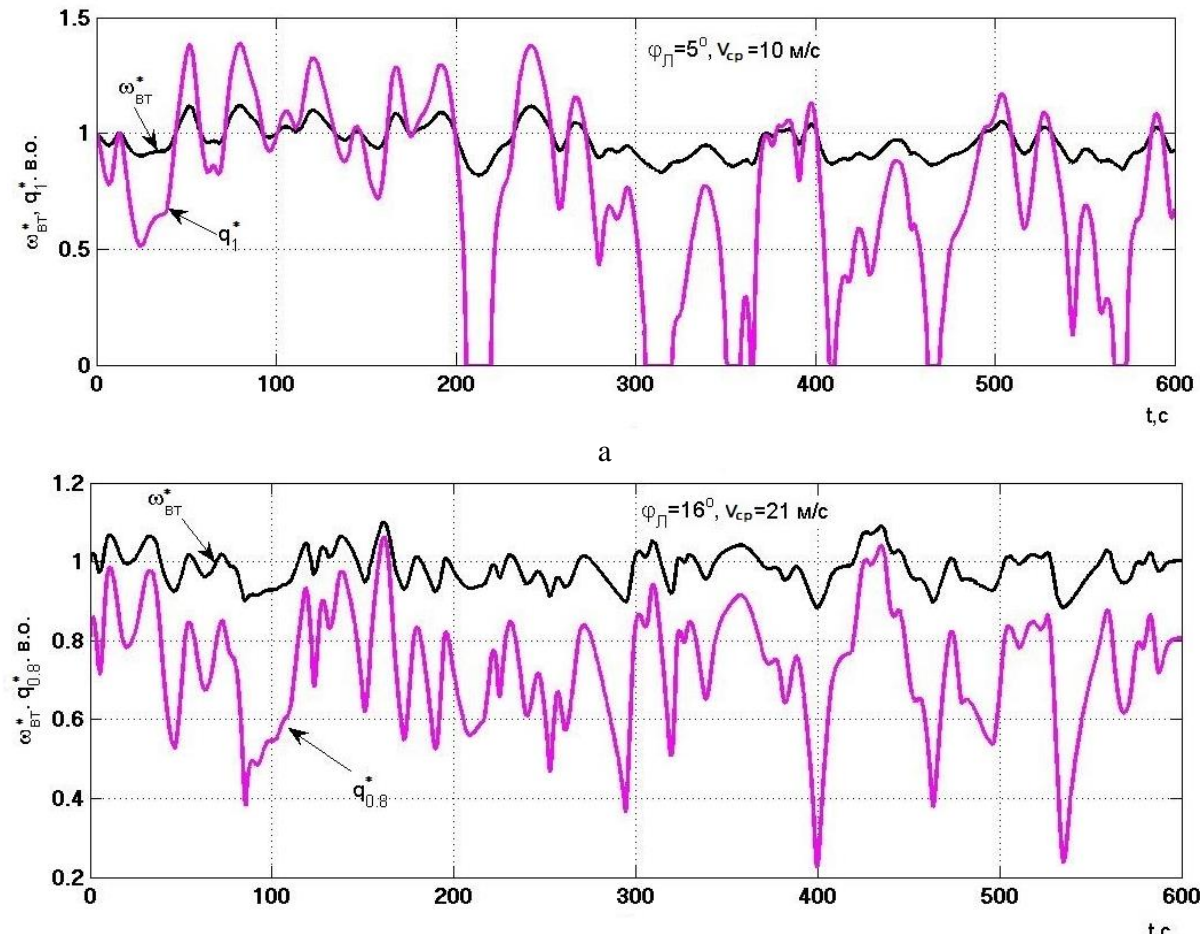

b

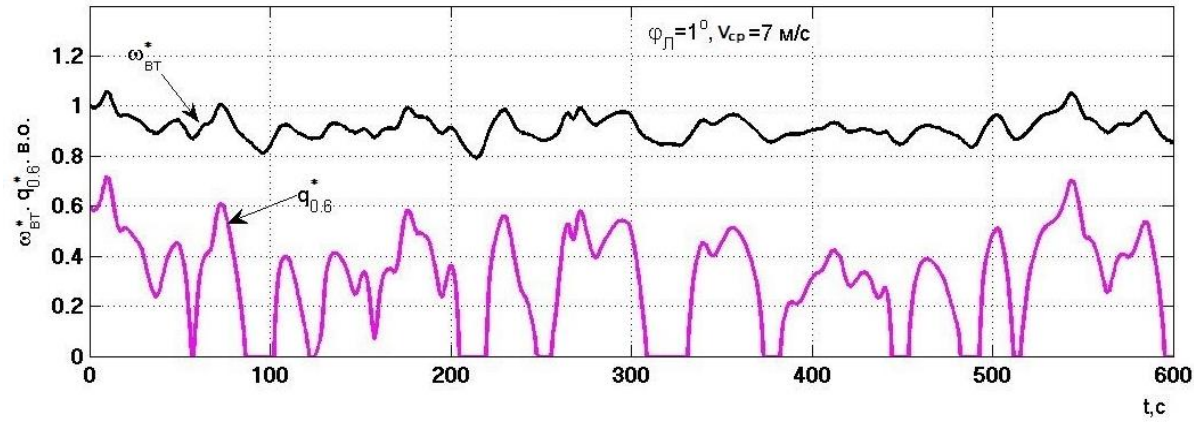

$\mathrm{c}$

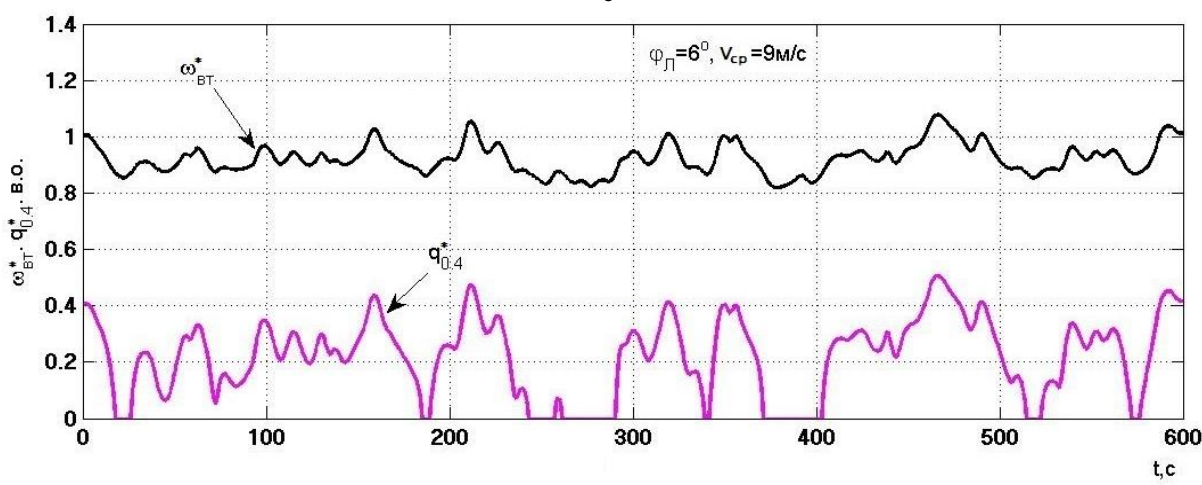

d

Рис. 2. Динаміка зміни частоти обертання ВТ і подачі насосу різної потужності.

Fig. 2. Dynamics of change of the frequency of rotation of the wind turbine and pump feed of a pump of different power.

Таблиця 2. Дані метеопостів.

Table2. Meteorological data.

\begin{tabular}{|l|c|c|c|}
\hline \multirow{2}{*}{$\begin{array}{c}\text { Пункт спостереження } \\
\text { метеопосту }\end{array}$} & \multicolumn{2}{|c|}{ Коефіцієнти розподілу Вейбула } & Середньорічна швидкість вітру, м/с \\
\cline { 2 - 4 } & $\gamma$ & $\alpha$ & $v_{c p}$ \\
\hline Маріуполь Порт & 5,0195 & 1,1 & 4.8 \\
\hline Херсонський маяк & 5,4214 & 1,17 & 5.1 \\
\hline Порт Південний & 4,428 & 1,68 & 3.9 \\
\hline Середнє значення & 4,9563 & 1,31 & 4,56 \\
\hline
\end{tabular}




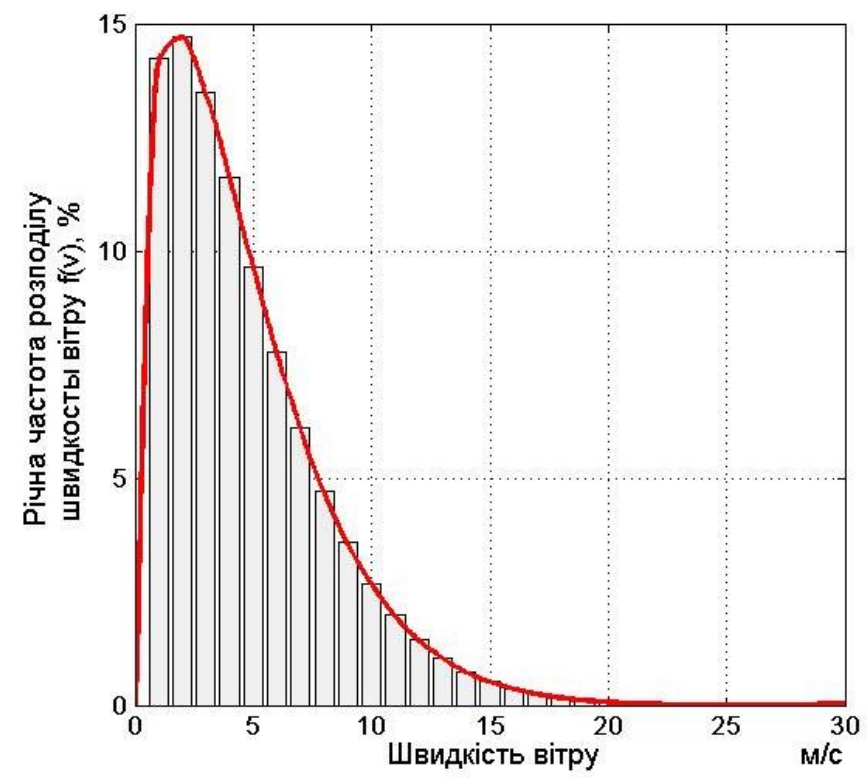

Рис. 3. Полігон частот двопараметричного розподілу Вейбула швидкості вітру за рік.

Fig. 3. The frequency polygon of the two parametric Weibull distribution of wind speed per year.

Визначено подачу $\left(\mathrm{q}_{\mathrm{j}}\right)$ кожного варіанту роботи ВТ і насосу згідно (2) для кожної градації вітру, яка представлена у вигляді гістограми (рис.4) в відсотковому відношенні. Тобто при співвідношенні потужності ВТ і насосу 1 до 1 на (рис.4а) значення 100\% відповідає номінальному режиму роботи ВНУ, а для інших співвідношень номінальним буде $-80 \%, 60 \%$ та $40 \%$.

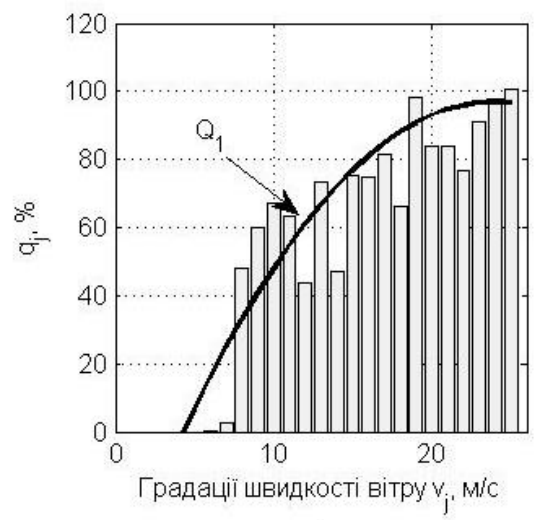

a

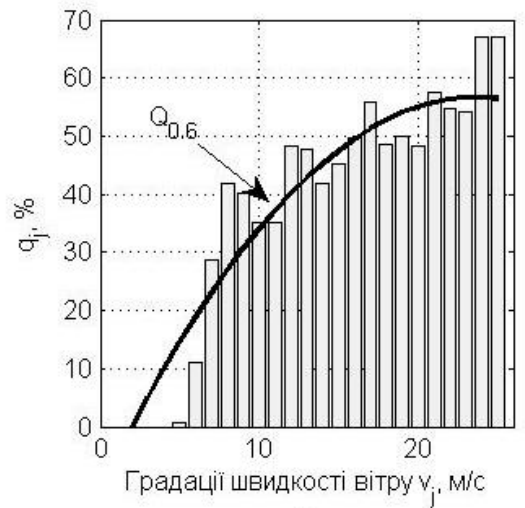

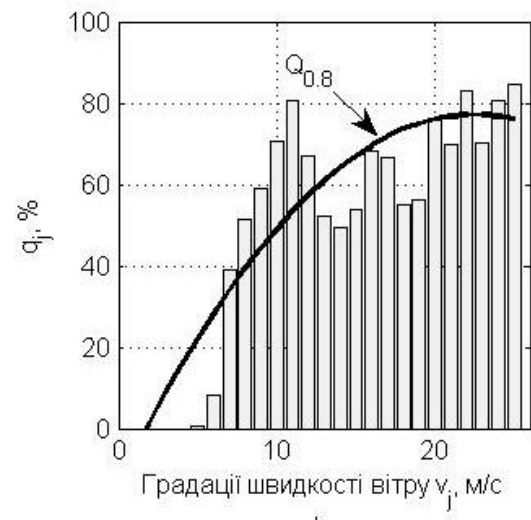

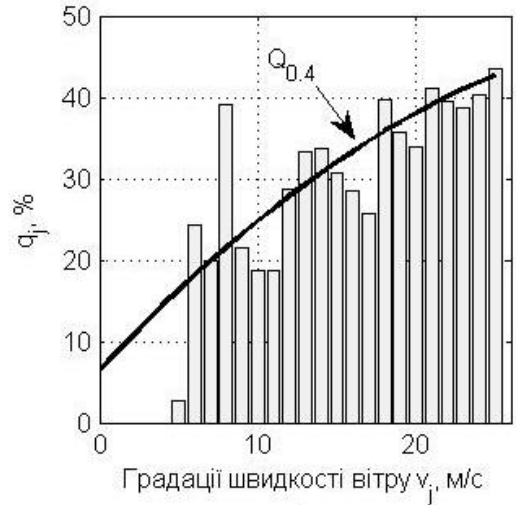

Рис. 4. Кількісний результат роботи насосу різної потужності на подачу при різних градацій вітру: $a-1: 1 ; b-1: 0.8 ; c-1: 06 ; d-1: 0.4$.

Fig. 4. Quantitative result of the pump operation at different power outputs at different wind rates: $a-1: 1 ; b-1: 0.8 ; c-1: 06 ; d-1: 0.4$. 
Показники подачі відповідно до рис.4 мають виражений тренд і описуються наступними рівняннями:

$$
\left[\begin{array}{ll}
\mathrm{Q}_{1}=-0.25 \cdot \mathrm{v}_{\mathrm{j}}^{2}+12 \cdot \mathrm{v}_{\mathrm{j}}-47, & 8 \leq \mathrm{v}_{\mathrm{j}} \leq 25 \mathrm{M} / \mathrm{c} ; \\
\mathrm{Q}_{0,8}=-0.18 \cdot \mathrm{v}_{\mathrm{j}}^{2}+8.1 \cdot \mathrm{v}_{\mathrm{j}}-14, & 7 \leq \mathrm{v}_{\mathrm{j}} \leq 25 \mathrm{M} / \mathrm{c} ; \\
\mathrm{Q}_{0,6}=-0.12 \cdot \mathrm{v}_{\mathrm{j}}^{2}+5.7 \cdot \mathrm{v}_{\mathrm{j}}-11, & 7 \leq \mathrm{v}_{\mathrm{j}} \leq 25 \mathrm{M} / \mathrm{c} ; \\
\mathrm{Q}_{0,4}=-0.026 \cdot \mathrm{v}_{\mathrm{j}}^{2}+2.1 \cdot \mathrm{v}_{\mathrm{j}}+6.4, & 6 \leq \mathrm{v}_{\mathrm{j}} \leq 25 \mathrm{M} / \mathrm{c} ;
\end{array}\right.
$$

Продуктивність перетворення вітрового потоку у кількісні значення подачі насосом різної потужності відповідно до річного розподілу Вейбула за виразом (1) наведені в табл. 3. Найкращий показник припадає на співвідношення номінальних потужностей ВТ і насосу 1:0,8, що в цілому пов'язане 3 продуктивнішою роботою на вітрах, менших номінального (9 м/с). Невисока продуктивність ВНУ даного співвідношення пояснюється тим, що вітроустановка розрахована на номінальний вітер зі швидкістю в 9 м/с, що має низьку частоту появи протягом року, коли найбільша частота припадає на вітри менші за 5 м/с.

Таблиця 3. Продуктивність сумісної роботи ВТ і насосу

Table 3. Productivity of compatible work of the wind turbine and the pump

\begin{tabular}{|c|c|c|c|c|}
\hline $\begin{array}{c}\text { Співвідношення номі- } \\
\text { нальних потужностей } \\
\text { ВТ і насосу, в.о. }\end{array}$ & $1: 1$ & $1: 0.8$ & $1: 0.6$ & $1: 0.4$ \\
\hline Продуктивності, W, \% & 10,65 & 13,95 & 10 & 8,39 \\
\hline
\end{tabular}

Найкращий результат продуктивності для номінальних співвідношень складових ВНУ (табл.3) вказує, що іiі робота на півдні України для заряду умовного басейну-акумулятора гідроакумулювальної електростанції коливається біля $14 \%$ в залежності від потужності насосу. Даний показник продуктивності залежить від тривалості номінальної і вище значень швидкості вітру на рік. Тому для його підвищення потрібно використовувати вітроустановку з вищим розміщення над рівнем землі вітрової турбіни, тому що зі збільшенням висоти збільшується $\mathrm{v}_{\text {cp. }}$ Спираючись на продуктивність досліджуваної установки, можна підібрати необхідну кількість таких установок для оцінки швидкості наповнення резервуару для конкретних умов, тощо.

Висновок. Досліджено використання енергії вітру для іiі гідроакумулювання 3 урахування пульсацій вітру. Визначено найпродуктивніший варіант ВНУ, що припадає на співвідношення номінальної потужності ВТ і насосу як 1 до 0,8 , а найгірший варіант придає на співвідношення 1 до 0,4. Кількісні показники роботи ВНУ за рік виражені через продуктивність подачі насосу і для найкращого співвідношення дорівнюють 14\% 3 врахуванням визначених обмежень в номінальному режимі роботи.

1. Красовский Н.В. Проблемы использования энергии ветра. Выпуск 43, изд. Науч. тех. управление ВСНХ Москва 1929.

2. Перли С.Б. Быстроходные ветряные двигатели. М. Госэнергоизд. 1951. $214 \mathrm{c.}$

3. Харитонов В.П. Автономные ветроэлектрические установки. М. 2006. 280 с.

4. Фатеев Е.M. Ветродвигатели и ветроустановки. М. Гос.изд.сельхоз. лит. 1957.536 с.

5. The future role and challenges of Energy Storage. Working Paper [Електронний pecypc]. European Commission, Directorate-General for Energy. Режим доступу: https://ec.europa.eu/energy/sites/ener/files/energy_storage.pdf.

6. Speicher und Pumpspeicherkraftwerke in Österreich [Електронний ресурс]. Universität Innsbruck. 2011. Режим доступу: https://www.unidue.de/imperia/md/content/wasserbau/30-11-aufleger.pdf.

7. D. Steward, G. Saur, M. Penev, and T. Ramsden. Lifecycle Cost Analysis of Hydrogen Versus Other Technologies for Electrical Energy Storage, Technical Report NREL/TP-56046719. November 2009.

8. Charles A. S. Hall. Energy Return on Investment. - Peжим доступу: http://energy-reality.org/wpcontent/uploads/2013/05/09_Energy-Return-onInvestment R1 012913.pdf

9. Charles J. Barnhart, *a Michael Dale,a Adam $R$. Brandtb and Sally M. Bensonab. The energetic implications of curtailing versus storing solar- and wind-generated electricity, Energy Environ. Sci.. 2013. No. 6. Pp. 2804-2810.

10. Pumped-hydro energy storage: potential for transformation from single dams, EUR 25239 EN. 2012.

11. Assessment of the European potential for pumped hydropower energy storage, EUR 25940 EN. 2013.

12. Pimm, Andrew J., Seamus D. Garvey, and Maxim de Jong. Design and testing of Energy Bags for underwater compressed air energy storag, Energy 2014. No. 66. Pp. 496-508.

13. Черных И.В. SIMULINK - Среда создания инженерных приложений. М. 2004. 496 с.

14.. Дьяконов В.П. MATLAB 6/6.1/6.5 + SIMULINK 4/5 в математике и моделировании. М. 2003.768 с.

15. Вербовий А.П., Пазич С.Т. Моделювання динамічних $\mathrm{i}$ квазістатичних режимів роботи вітроводонасосної установки 3 урахуванням стохастичної складової швидкості вітру. Відновлювана енергетика. 2018. №4(55). C. $25-33$.

16. Васько П.Ф. Розрахунок показників технічної ефективності застосування вітроелектричних установок за результатами строкових вимірювань швидкості вітру. Технічна електродинаміка. 2001. №6. С. 45-49.

17. Брыль А.А., Васько П.Ф., Пекур П.П. Определение технических показателей эффективности использования ветроэлектрических агрегатов в Украине. Энергетика и электрификация. 1995. №2. С. 48-51.

18. ДСТУ IЕС 61400-12-2001. Системи турбогенераторні вітряні. Частина 12. Випробування вітряних турбін для визначення енергетичних характеристик. (IEC 6140011:1998, IDT). Введ. 01.07.2003 p. К. Держспоживстандарт України. 2003. $31 \mathrm{c.}$

19. Васько В.П., Васько П.Ф. Динамика нагрузочных режимов работы ветроэлектрической установки, обусловленная порывами ветра. Вісник Донбаської державної академії будівництва і архітектури. Зб. наук. праць. 2001. № 4 (29). C. 140-144. 
20. Кінаш Р. I., Бурнаєв О. М. Вітрове навантаження вітроенергетичні ресурси в Україні. Львів: Вид. наук.-техн. літ. 1998. $1152 \mathrm{c}$.

21. Васько П.Ф., Вербовий А.П., Пазич С.Т. Реалізація стохастичної моделі поздовжньої складової швидкості вітру для задач вітроенергетики. Відновлювана енергетика. 2017 №3. С. 54-61.

22. Денисенко Г.И., Васько П.Ф., Пекур П.П. Стохастическое моделирование параметров ветра для задач ветроэнергетики. Известия АН СССР Энергетика и транспорт. 1990. №2. С. 109-115.

23. Пазич C.T. Апроксимація аеромеханічних характеристик вітрової турбіни вітроводонасосної установки в навантажувальних режимах роботи методом заміни змінних. Відновлювана енергетика. 2018. №1(52). С.62-69.

24. Knapp R.T., Complete Characteristics of Centrifugal Pumps and Their Use in the Prediction of Transient Behaviour Trans. ASME. 1937. Vol. 59. Рp. 683-689. [Електронний ресурс]. Режим доступу: https://pdfs.semanticscholar.org/040c/1c6d2402664250f84839fb 380d32944cd049.pdf. (Дата звернення: 28.05.2019).

25. Степанов А.И. Центробежные и осевые насосы. М Машгизд. 1960. $464 \mathrm{c}$.

\section{REFERENCE}

1. Krasovsky N.V. Problemy ispolzovaniya energii vetra [Problems of using wind energy]. Issue 43. ed. Sci. tech. administration. VSNH. Moscow. 1929. [in Russian].

2. Perli S.B., Bystrokhodnyye vetryanyye dvigateli [High speed wind turbines]. Moscow. Gosenergoizdat. 1951. 214 p. [in Russian].

3. Haritonov V.P. Avtonomnyie vetroelektricheskie ustanovki. [Autonomous wind power plants]. Moscow. 2006. 280 p. [in Russian].

4. Fateev E. $M$. Vetrodvyhately y vetroustanovky [Windmills and wind turbines]. Moscow. GOS.ed.agricultural lit.. 1957.536 p. [in Russian].

5. The future role and challenges of Energy Storage. Working Paper [Electronic resource], European Commission, Directorate-General for Energy, Retrived from https://ec.europa.eu/energy/sites/ener/files/energy_storage.pdf. [in English].

6. Speicher und Pumpspeicherkraftwerke in Österreich [Electronic resource]. Universität Innsbruck. 2011. Retrived from https://www.uni-due.de/imperia/md/content/wasserbau/3011-aufleger.pdf). [in English].

7. D. Steward, G. Saur, M. Penev, and T. Ramsden. Lifecycle Cost Analysis of Hydrogen Versus Other Technologies for Electrical Energy Storage, Technical Report NREL/TP-56046719. November. 2009. [in English].

8. Charles A. S. Hall. Energy Return on Investment. Retrived from http://energy-reality.org/wpcontent/uploads/2013/05/09 Energy-Return-onInvestment_R1_012913.pdf. [in English].

9. Charles J. Barnhart, *a Michael Dale, a Adam $R$ Brandtb and Sally $M$. The energetic implications of curtailing versus storing solar- and wind-generated electricity Bensonab, Energy Environ. Sci. 2013. No. 6. Pp. 2804-2810. [in English].

10. Pumped-hydro energy storage: potential for transformation from single dams. EUR 25239 EN. 2012. [in English].

11. Assessment of the European potential for pumped hydropower energy storage. EUR 25940 EN. 2013. [in English].

12. Pimm, Andrew J., Seamus D. Garvey, and Maxim de Jong. Design and testing of Energy Bags for underwater compressed air energy storag. Energy 2014. No. 66 Pp. 496508. [in English].
13. Chernyih I.V. SIMULINK - Sreda sozdaniya inzhenernyih prilozheniy. [Environment for creating engineering applications] Moscow. Dialog. MIFI. 2004, 496 p. [in Russian].

14. Dyakonov V.P. MATLAB 6/6.1/6.5 SIMULINK 4/5 v matematike i modelirovanii. [MATLAB 6/6.1/6.5 + SIMULINK 4/5 in mathematics and modeling], Moscow: Solon-Press. 2003. 768 p. [in Russian].

15. Verbovyi A.P., Pazych S.T. Modelyuvannya dinamichnikh i kvazistatichnikh rezhimiv roboti vitrovodonasosnoï ustanovki z urakhuvannyam stokhastichnoï skladovoï shvidkosti vitru. [Modeling of dynamic and quasistatic modes of the work of a wind pump installation with consideration of stochastic compound wind speed] Vidnovluvana energetika. 2018. No. 4. Pp. 26-33. [in Ukrainian].

16. Vasko P.F. Razrakhunok pokaznykiv tekhnichnoyi efektyvnosti zastosuvannya vitroelektrychnykh ustanovok za rezul'tatamy strokovykh vymiryuvan' shvydkosti. [Calculation of the technical efficiency of the application of wind power installations based on the results of term velocity measurements], Tekhnichna elektrodynamika. 2001. No. 6. Pp. 45-49. [in Ukrainian]

17. Bryl A.A., Vasko P.F. Pekur P.P., Opredelenie tehnicheskih pokazateley effektivnosti ispolzovaniya vetroelektricheskih agregatov v Ukraine. [Definition of technical indicators of efficiency of use the wind-electric aggregates in Ukraine]. Energy and Electrification. 1995. No. 2. Pp. 48-51. [in Russian].

18. IEC 61400-12-1998 Wind turbine generator systems. Part 12. Wind turbine power performance testing.

19. Vasko. V.P. Vasko, P.F. Dynamika nagruzochnyih rezhimov rabotyi vetroelektricheskoy ustanovki, obuslovlennaya poryivami vetra. [Dynamics of loading modes of the windelectric installation, caused by gust of wind]. Bulletin of the Donbas State Academy of Building and Architecture. Collection of scientific work. 2001. No. 4(29). Pp. 140-144. [in Russian].

20. Kinash R.I.. Burnaєv O. M. Vitrove navantazhennya i vitroyenergetichni resursi $\mathrm{v}$ Ukraini. [Wind load and wind energy resources in Ukraine]. Lviv. View. Sci.-Tech. Lit. 1998. 1152 p. [in Ukrainian].

21. Vasko P.F., Verbovyi A.P., Pazych S.T. Realizatsiia stokhastychnoi dvoparametrychnoi modeli pozdovzhnoi skladovoi shvydkosti vitru dlia zadach vitroenerhetyky. [Implementation of a stochastic two-parameter model of the longitudinal component of the wind speed for wind power problems]. Vidnovluvana energetika. 2017. No. 3. Pp. 54-61. [in Ukrainian]

22. Denisenko G.I., Vasko P.F., Pekur P.P., Stohasticheskoe modelirovanie parametrov vetra dlya zadach vetroenergetiki. [Stochastic simulation of wind parameters for wind power projects]. Bulletin of the Academy of Sciences of the USSR Energy and Transport. 1990. No. 2. Pp. 109-115. [in Russian].

23 Pazych S.T. Aproksimatsiya ayeromekhanichnikh kharakteristik vitrovoï turbini vitrovodonasosnoï ustanovki v navantazhuvalnikh rezhimakh roboti metodom zamini zminnikhs. [Approximation of aeromechanical characteristics of the wind turbine of a wind pump installation in the load operation modes by the method of changing the variables]. Vidnovluvana energetika. 2018. No.1. Pp.62-69. [in Ukrainian].

24. Knapp R.T. Complete Characteristics of Centrifugal Pumps and Their Use in the Prediction of Transient Behaviour, Trans. ASME, 1937. Vol. 59, pp. 683-689. [Electronic resource]. Retrived from https://pdfs.semanticscholar.org/040c/1c6d2402664250f84839fb 380d32944cd049.pdf. Applaing date 26.12.2018. [in English].

25. Stepanoff A.I. Tsentrobezhnyieiosevyienasosyi [Centrifugal and axial flow pumps]. Moscow. Mashgiz. 1960. 464 p. [in Russian]. 


\section{МОДЕЛИРОВАНИЕ ПРОЦЕССА ЗАРЯДА БАСЕЙНА-АККУМУЛЯТОРА ГИДРОАКУМУЛИРУЮЩЕЙ ЭЛЕКТРОСТАНЦИИ ОТ ВЕТРОВОДОНАСОСНОЙ УСТАНОВКИ}

\section{С.Т. Пазыч}

Институт возобновляимой энергетики НАН Україны 02094 вул. Гната Хоткевича, 20А, м. Киев.

C ростом доли возобновляемых источников 6 электроэнергетической сети Украины, происходит негативное влияние на качество электрической энергии так и на саму сеть. Одним из эффективных вариантов интеграчии возобновляемых источников в электроэнергетическую сеть это аккумулировать ее энергию с последуюшим использованием. Поскольку основной проблемой возобновляемых источников является ее непостоянство $u$ пульсаиия во времени, то ее аккумулирования в такие периоды приемлемый вариант. В Украине наибольшую долю по выработке за год занимают ветроэлектрическ станции, что в основном находятся на юге Украины. Там концентрачия крупных ветроэлектрических станций обусловливают нестационарная работу электрической сети, в свою очередь приводит к их отключения при больших пульсациях генерирования электрической энергии. Аккумулирования энергии ветра возможно в различных исполнениях, но в данном исследовании изучается вариант с гидроакумулюванням этой энергии для последуюшим использованием через гидравлическую турбину. То есть исследоваться проиесс преобразования энергии ветра в количественные показатели накопления воды в течение определенного времени. В качестве объекта исследования будет выступать витроводонасосна установка. Моделирование такого прочесса будет происходить из сочетания трех составляюших: модели ветра, модель ветровой турбины, модель насоса. Моделирование будет осуществляться для различных мощностей насоса при постоянной мощности ветроустановки для определения наиболее эффективного варианта работь витроводонасонои установки. Для соотношения различных вариантов витроводонасоснои установки с различными мощностями насосов использовать относительные единищы измерения, поскольку характеристики насосов в относительных единицах идентичны в пределах одного класса. Параметром, которым будет оиениваться работа витроводонасоснои установки служить годовая величина производительности данной установки в прочентном отночении при годовом распределения энергии ветра для выбранного региона. Работа установки моделироваться только при нормальном режиме работы с учетом пульсаций ветра и ограничений 6 моделировании работы ветровой турбины и насоса из опыта их эксплуатации. Бібл. 25., табл. 3, рис. 4.

Ключевые слова: ветроводонасосная установка, механическая характеристика, модель, момент, подача, пульсаиии.

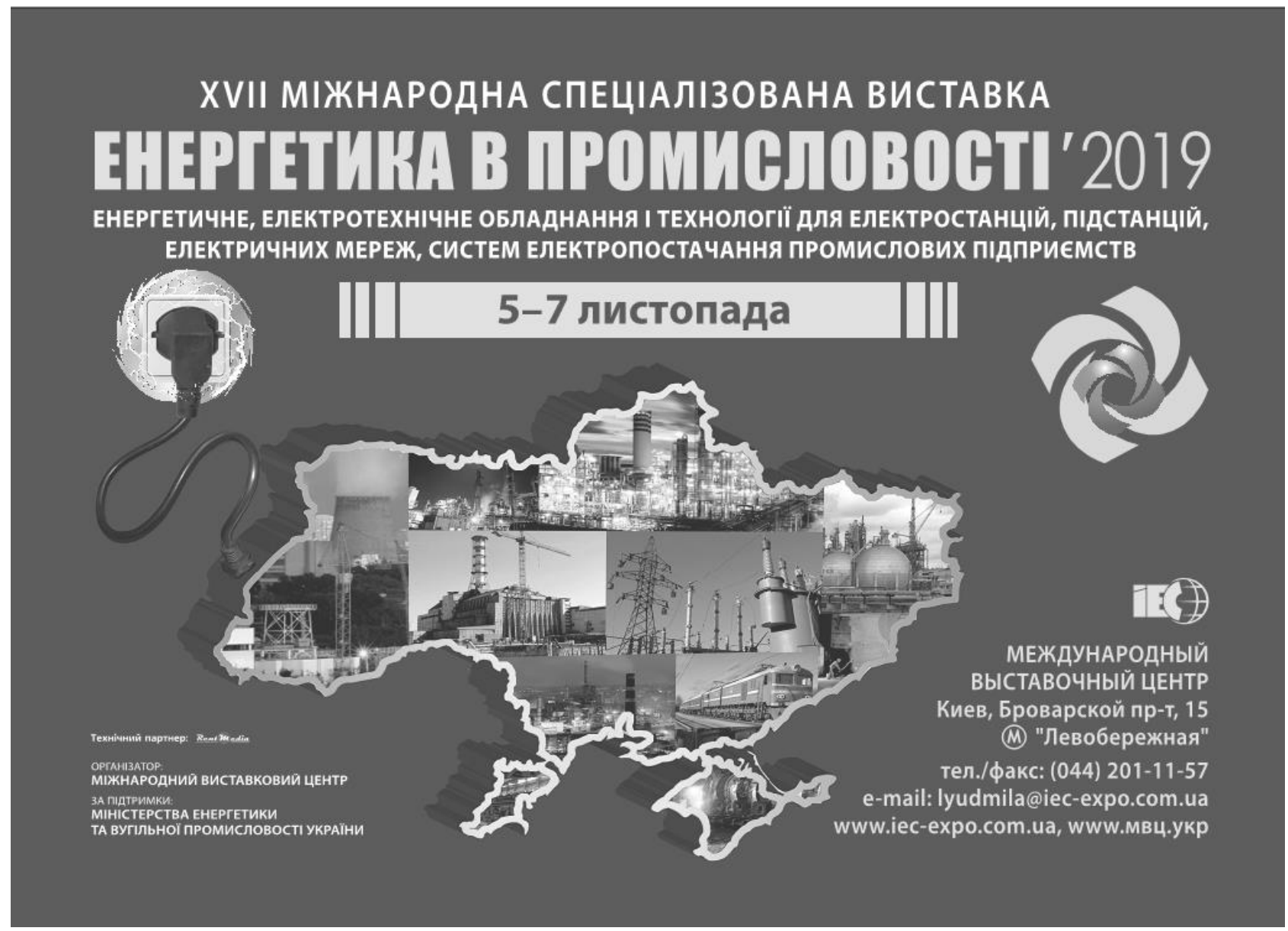

